\title{
Corpo, Tempo, Espaço e Outro como Condições de Possibilidade do Vivido
}

\author{
(Psico)patológico
}

\author{
Camila Pereira de Souza* \\ Universidade de Fortaleza - Unifor, Fortaleza, CE, Brasil \\ ORCID: http://orcid.org/0000-0002-5901-9182 \\ Lucas Guimarães Bloc** \\ Universidade de Fortaleza - Unifor, Fortaleza, CE, Brasil \\ ORCID: https://orcid.org/0000-0002-8528-131X \\ Virginia Moreira*** \\ Universidade de Fortaleza - Unifor, Fortaleza, CE, Brasil \\ ORCID: https://orcid.org/0000-0003-2740-0023
}

\section{RESUMO}

Corpo, tempo, espaço e Outro são as bases que constituem nossa experiência intersubjetiva. Nomeadas aqui como categorias fenomenológicas, elas são uma ferramenta para a compreensão do mundo vivido (psico)patológico, pois em suas alterações se desvelam a estrutura da experiência de adoecer. Este artigo tem como objetivo desenvolver um estudo teórico a respeito das condições que possibilitam o aparecimento dos mundos vividos (psico)patológicos na perspectiva de uma fenomenologia clínica da ambiguidade. A perda de comunicação vital com o mundo característica das alterações corporais, a dessincronização da experiência temporal, o espaço vazio e sem significações atrelado a um prejuízo na relação dialética Eu-Outrem forma o eixo nuclear de sustentação dos mundos vividos (psico)patológicos, ilustrados aqui por meio dos modos de funcionamento na depressão melancólica e na esquizofrenia. Concluímos que estas categorias se atravessam mutuamente e sua divisão é apenas de ordem didática. Elas precisam ser compreendidas globalmente para alcançarmos as experiências de adoecer.

Palavras-chave: fenomenologia, clínica, psicopatologia.

\section{Body, Time, Space and Other as Possibility of (Psycho)pathological Lived}

\begin{abstract}
Body, time, space and Other are the bases that constitute our intersubjective experience. Named here as phenomenological categories, they are a tool for understanding the lived (psycho)pathological world, as these changes can result in an adornment experience structure, as the changes can result in a structure of experience of illness. This article aims to develop a theoretical study about the conditions that enable the emergence of the (psycho)pathological lived world from the perspective of a clinical phenomenology of ambiguity. The loss of vital
\end{abstract}

ISSN 1808-4281 
communication with the world that is characteristic of bodily changes, the desynchronization of temporal experience, the empty and meaningless space linked to a loss in the I-Other dialectical relationship forms the nuclear axis of support of the (psycho)pathological worlds, illustrated here through the modes of functioning in melancholic depression and schizophrenia. We conclude that these categories cross each other and their division is only didactic. They need to be understood globally to reach the experiences of falling ill.

Keywords: phenomenology, clinic, psychopathology.

\title{
Cuerpo, Tiempo, Espacio y Otro como Posibilidad del Vivido
}

\author{
(Psico)patológico
}

\section{RESUMEN}

El cuerpo, el tiempo, el espacio y el Otro son las bases que constituyen nuestra experiencia intersubjetiva. Nombradss aquí como categorías fenomenológicas, son una herramienta para comprender el mundo vivido (psico)patológico ya que en sus cambios se revela la estructura de la experiencia de enfermarse. Este artículo tiene como objetivo desarrollar un estudio teórico sobre las condiciones que permiten la aparición de mundos vividos (psico)patológicos en la perspectiva de una fenomenología clínica de la ambigüedad. La pérdida de la comunicación vital con el mundo característico de las alteraciones corporales, la desincronización de la experiencia temporal, el espacio vacío y sin sentido vinculado a una pérdida en la relación dialéctica Yo-Otro forma el eje nuclear de soporte de los mundos vividos (psico)patológicos, ilustrado aquí a través de los modos de funcionamiento en la depresión melancólica y la esquizofrenia. Encontramos que estas categorías se cruzan entre sí y su división es solo didáctica. Deben entenderse globalmente para alcanzar las experiencias de enfermarse.

Palabras clave: fenomenología, clínica, psicopatología.

A fenomenologia, como corrente filosófica, surge com os trabalhos do filósofo Edmund Husserl. De origem tcheca e tendo realizado seu percurso acadêmico na Alemanha, Husserl tinha como intuito tecer estudos sobre os fenômenos em seus modos de aparecimento à consciência e, para isto, construiu críticas ao empirismo e à ciência positivista de sua época, os quais desconsideravam a subjetividade como modo de apreensão do mundo (Zahavi, 2015).

Os escritos de Husserl (1928/1994; 1954/2012) para a fenomenologia filosófica inspiraram outros filósofos a desenvolverem este campo filosófico, epistemológico e metodológico. Dentre eles, encontramos nomes como Martin Heidegger, Maurice Merleau- 
Ponty e Jean-Paul Sartre, os quais representam um marco na tradição fenomenológica em filosofia (Zahavi, 2015).

A fenomenologia filosófica foi um campo tão fértil que, em meados dos anos 1920, ela transbordou o eixo filosófico e atingiu a clínica, inicialmente, através da psiquiatria. Psiquiatras europeus descobriram nestes escritos filosóficos uma via para a compreensão do adoecimento mental que poderia ultrapassar o viés linear, classificatório e de causa e efeito vigente no saber médico psiquiátrico da época (Bloc, Moreira, Wolf-Fédida, \& Chamond, 2017) e promover um olhar compreensivo, crítico e, sobretudo, clínico ao ter como foco a experiência de adoecimento e o encontro clínico.

Com os trabalhos de Eugène Minkowski e Ludwig Binswanger no célebre evento da $63^{a}$ sessão da Sociedade Suíça de Psiquiatria em Zurique, em 1922, inaugurou-se o campo da fenomenologia psiquiátrica ou psicopatologia fenomenológica (Tatossian, 1979/2006). No cenário contemporâneo, além da psiquiatria e da psicopatologia, podemos inserir também os trabalhos em psicologia clínica e psicoterapia de inspiração fenomenológica, ampliando o leque clínico e permitindo a nomeação contemporânea de uma fenomenologia clínica (Bloc et al., 2017).

Desde o seu surgimento, atrelado à psicopatologia fenomenológica, a fenomenologia clínica tem contribuído significativamente com estudos clínicos sobre a esquizofrenia, depressão, ansiedade, transtornos alimentares, entre outros. Como ponto comum, tais estudos se voltam para as condições de possibilidade do vivido (psico)patológico. Trata-se dos fundamentos que constituem nossa existência entrelaçada ao mundo, a saber: o corpo, o tempo, o espaço e o outro (Tatossian, 1983/2012a, 1994; Messas, Tamelini, Mancini, \& Stanghellini, 2018). Uma abordagem fenomenológica da psicopatologia descreve as alterações da estrutura da experiência de adoecer (Irarrázaval, 2018), o que nomeamos como categorias fenomenológicas. Estas são uma ferramenta para a compreensão diagnóstica que, através de uma lente fenomenológica, possibilita a compreensão do mundo vivido (psico)patológico.

Embora didaticamente separadas, estas categorias se entrelaçam e, ainda que historicamente os escritos em psicopatologia fenomenológica se voltem para a dimensão do tempo vivido (Minkowski, 1933/1994, Binswanger, 1960/2005, Tatossian, 1979/2006), o estudo em conjunto das categorias permite uma compreensão mais ampla da experiência de adoecer. Elas não devem ser confundidas ou resumidas como experiências conscientes, pois estão no fundamento da existência humana (Tatossian, 1979/2006). 
Para além da descrição do vivido, a fenomenologia clínica visa a apreender as estruturas de subjetivação desta experiência, pois suas alterações constituem os mundos vividos (psico)patológicos (Tatossian, 1979/2006; Messas et al., 2018). Neste artigo, temos como objetivo apresentar o corpo, o tempo, o espaço e o outro como condições de possibilidade do vivido (psico)patológico. Como forma de ilustrar o uso das categorias como via de compreensão da experiência patológica, discutimos ainda estas alterações no vivido depressivo e esquizofrênico.

As discussões sobre o corpo, o tempo, o espaço e o outro como dimensões da existência atravessam amplamente a história da filosofia e também as discussões dos diferentes fenomenólogos. Neste artigo, optamos por utilizar como eixo a lente de uma fenomenologia clínica da ambiguidade, mais especificamente as contribuições de Maurice Merleau-Ponty, como inspiração oriunda do campo da filosofia, de Arthur Tatossian que, além de trazer uma perspectiva ambígua da psicopatologia, recorre ao eixo das categorias como referencial clínico, e de autores contemporâneos que recorrem às categorias fenomenológicas como eixo de compreensão da experiência de adoecer. Com este artigo, visamos contribuir para preencher a lacuna de necessários estudos que possam sistematizar essas diferentes dimensões do mundo vivido em que toda experiência de adoecer está situada.

\section{O Corpo}

A dimensão corporal possui lugar de destaque na fenomenologia, pois "toda experiência mundana é mediada e possibilitada por nossa corporeidade" (Zahavi, 2015, p. 146). Pode-se dizer que a ênfase sobre o corpo perpassa a fenomenologia desde Husserl (1954/2012) e assume um ponto de destaque com Merleau-Ponty (1945/2006b).

Ao desenvolver uma fenomenologia filosófica da ambiguidade, Merleau-Ponty (1942/2006a; 1945/2006b) situa o corpo como fio condutor do enraizamento do ser humano no mundo ao assumir o lugar de uma consciência encarnada, ou seja, diluída na própria corporeidade. Encarnada no corpo, a subjetividade constituindo-se como intersubjetividade (Merleau-Ponty, 1945/2006b).

O esforço fenomenológico é de evidenciar o corpo como a sede da experiência vivida. Husserl (1954/2012) apresenta uma distinção entre duas formas de experienciar a corporeidade, a saber: Leib e Körper, respectivamente, corpo sujeito e corpo objeto. Esta distinção husserliana é resgata por Merleau-Ponty (1942/2006; 1945/2006) e se torna um eixo fundamental para a compreensão do Lebenswelt. 
O corpo sujeito (Lieb) possui um dado originário de nossa existência encarnada ao ser constituído e constituinte de nossa relação com o mundo, revelando a vivência do sujeito em seu próprio corpo, uma experiência em primeira pessoa. Já o corpo objeto corresponde ao corpo como coisa ou como instrumento que o sujeito tem à sua disposição, inclusive do ponto de vista biológico, e que possibilidade o contato com o outro a partir, por exemplo, de sua visibilidade (Husserl, 1954/2012; Merleau-Ponty, 1945/2006b; Tatossian, 1982/2012c; 1983/2012a). Compreender a corporeidade é vislumbrar a totalidade do corpo vivido por meio da complementaridade, e mesmo do desejável equilíbrio, entre corpo objeto e corpo sujeito (Tatossian, 1982/2012c, 1983/2012a).

Esta distinção nasce no eixo filosófico da fenomenologia e recai na área clínica, pois o desequilíbrio na relação entre corpo sujeito e corpo objeto implica no desvelamento de experiências psicopatológicos (Tatossian, 1979/2006; Messas et al., 2018), uma vez que é na sincronização dessas duas facetas da corporeidade que a subjetividade se constitui como intersubjetividade. O corpo objeto é parte integrante do corpo sujeito, não se resumindo ao soma (Merleau-Ponty, 1942/2006a; 1945/2006b). O caráter objetal do corpo é um ponto de partida para se pensar a subjetividade, pois é por meio dele que se adquire a capacidade de abertura ao mundo, à possibilidade de agir sobre o mesmo e, sobretudo, de permitir uma intersubjetividade (Tatossian, 1982/2012c). Se através do corpo vivemos nossa condição de encarnação, é o corpo objeto que permite o contato vital com o mundo.

Entre os animais, percebe-se uma exclusividade atribuída ao corpo sujeito, cuja identificação ao corpo é total e constitui uma subjetividade apenas corporal, na qual as significações são aquelas de sua espécie. Já o ser humano só se funda enquanto tal devido às suas significações individuais e, simultaneamente, histórico-culturais, que só são possíveis devido a uma subjetividade também individual, constituída na interseção da relação entre corpo sujeito e corpo objeto. Por poder se distanciar de sua identidade corporal imediata, o sujeito pode se afastar de seu corpo e olhar para si, como em um espelho, ou se ver como Outrem o vê, alcançando uma intersubjetividade própria da existência humana (Tatossian, 1982/2012c, 1983/2012a).

Pode-se dizer que não há nada que não seja produzido no corpo e através do corpo. Nas palavras de Merleau-Ponty (1945/2006b), “tudo reside ali” (p. 268), este é o problema, e mesmo o drama, do corpo próprio que é, necessariamente, ao mesmo tempo, sujeito e objeto. Falar da ambiguidade do corpo pode parecer natural, sobretudo, se consideramos a dimensão de um equilíbrio, tido como saudável, entre o corpo sujeito e o corpo objeto, ou como se utiliza Tatossian (1979/2006) o corpo que somos e o corpo que temos. Entretanto, é preciso 
considerar a possibilidade de um desequilíbrio, de uma desproporção que possibilita experiências psicopatológicas.

Se o corpo, como acena Merleau-Ponty (1942/2006a; 1945/2006b) ao longo de suas obras, nos abre possibilidades, ele também pode implicar um fechamento, uma inibição na comunicação vital com o mundo, como encontramos no vivido depressivo. Ou uma fragmentação, uma perda da encarnação de sua corporeidade como ocorre na esquizofrenia (Tatossian, 1979/2006). Tais experiências apontam para a necessidade de uma perspectiva clínica que leve em consideração a experiência corporal e a busca de um equilíbrio entre o corpo sujeito e o corpo objeto. Reapropriar-se do corpo como via de contato consigo, com o outro e com o mundo é tarefa da clínica de inspiração fenomenológica.

\section{O Tempo}

Discussões sobre o tempo são tão antigas quanto à história da humanidade, mas encontramos as primeiras indagações a seu respeito no campo da filosofia. Estas discussões alcançaram a fenomenologia filosófica com os trabalhos de Husserl (1928/1994), Heidegger (1927/2015), Merleau-Ponty (1945/2006b), dentre outros.

A grande questão que abre os estudos sobre o tempo na fenomenologia filosófica é a sua objetivação (Zahavi, 2015). Mensuramos o tempo com as batidas do relógio, mas seria essa a única forma de o experienciar? O entrelaçamento ambíguo do ser humano ao mundo se constitui na duração dos próprios fenômenos que se apreende (Merleau-Ponty, 1945/2006b). Isto faz referência ao tempo pessoal e subjetivo, a saber: o tempo vivido (Zahavi, 2015). Este tem um papel central no processo de subjetivação humana, pois é o fio condutor de sua intencionalidade ao pôr nossas experiências em movimento (Merleau-Ponty, 1945/2006b). Ao falarmos em tempo vivido, não nos referimos ao tempo cronológico e "das coisas" do mundo exterior. Tentamos compreender um tempo vital e imediato, atrelado ao devir e posto a nível pré-consciente, pois é o tempo da vida (Merleau-Ponty, 1945/2006b; Minkowski, 1933/1994; Tatossian, 1979/2006).

Vale ressaltar que os estudos fenomenológicos do tempo são inaugurados com os trabalhos de Eugène Minkowski, médico psiquiátrico que apresenta o tempo vivido como eixo central do adoecimento mental. Ideia esta inédita até então no campo da fenomenologia psiquiátrica (Melo, Araújo, Bloc, \& Moreira, 2016). Minkowski (1933/1994) atrela o tempo ao devir quando este escapa à passagem cronológica dos relógios. Ele é marcado pela fluidez, transitoriedade e um contínuo processo de vir a ser no sentido experiencial, impossibilitando a 
apreensão deste fenômeno pela racionalidade marcada na ideia de sucessão entre passado, presente e futuro. Estas, mais do que dimensões interligadas numa cadeia de sucessões, fazem parte de uma síntese temporal una e inquebrável (Husserl, 1928/1994; Merleau-Ponty, 1945/2006b). Há um senso de unidade nesta síntese que formam uma estrutura temporal fundamental diante da qual o tempo é imanente à consciência e vice-versa (Tatossian, 1979/2006).

A clássica cadeia de sucessões entre passado, presente e futuro possui uma problemática. Como afirma Tatossian (1979/2006), a "presença do passado e do futuro não está na atualidade, mas em imagem; passado e futuro não são mais do que presentificações" (p. 154). Em outras palavras, estas dimensões permitem conservar o que não é mais, ou seja, o que já passou (lembrança) ou que ainda virá (expectativa).

A permanência ilusória do passado com a conservação de algo que já foi e do futuro com a expectativa do porvir acarreta um alargamento do presente. Esta síntese temporal foi nomeada por Husserl (1928/1994) de retenção (conservação do que já foi), apresentação (perspectiva atual) e protensão (expectativa do que virá). Retenção e protensão são, respectivamente, condições de possibilidade do passado e do futuro, e não eles em si (Tatossian, 1979/2006).

Enquanto Husserl (1928/1994) dá lugar de destaque às investigações sobre a retenção no arco intencional, Merleau-Ponty (1945/2006b) elabora significativo complemento a estes estudos ao dar um papel mais ativo à rede de protensões na síntese da estrutura temporal da experiência do tempo. Este elemento será fundamental no campo da fenomenologia clínica ao explicitar o tempo sempre em estado nascente como horizonte de infinitas possibilidades (Melo et al., 2016). O ser humano, vivendo nessa síntese temporal, ultrapassa a linearidade do instante agora e constrói sua própria posição diante a imensidão do horizonte do tempo. Quando esse fluxo se altera, estabelecem-se os vividos (psico)patológicos, seja por meio da aceleração ou da retardação do vivido temporal, as quais fomentam uma existência estagnada, paralisada (Fuchs, 2010; 1014).

Ao compreendermos o tempo no sentido da intersubjetividade, ultrapassamos a lógica direcional que o orienta entre passado e futuro e seguimos para alcançar sua ordem relacional, em que o tempo pessoal e vivido interage e ressoa no tempo de outrem e no tempo do mundo (Minkowski, 1933/1994; Tatossian, 1979/2006; 1994; Fuchs, 2010). Pensar uma psicopatologia da intersubjetividade no tempo vivido é um caminho para a fenomenologia clínica e traz implicações diretas à prática clínica, pois esta se configura como possibilidade 
de ressincronização da experiência temporal no entrelaçamento dos mundos vividos do clínico e de seu paciente.

\section{O Espaço}

Atrelado ao tempo, o espaço se configura como uma categoria imprescindível para a compreensão da experiência patológica. A correlação entre tempo e espaço remonta estudos no campo da física e da matemática, e recaem numa discussão filosófica em fenomenologia (Husserl, 1954/2012; Merleau-Ponty, 1942/2006a; 1945/2006b). Se no tempo repousa a própria existência, que se desvela num horizonte contínuo e ininterrupto, o desenrolar de tal caminhada só é possível no espaço (Merleau-Ponty, 1945/2006b).

O espaço funciona como uma espécie de teia, um elo que conecta os fios de intencionalidade de nossas experiências por meio do engajamento do ser humano no mundo. Como assinala Merleau-Ponty (1945/2006b), "o espaço está assentado em nossa facticidade” (p. 342). Em outras palavras, não se trata de pensar o espaço como uma ponte ou um fio condutor, mas ele é o palco sob o qual o espetáculo da vida se orienta sem nunca precisar aparecer concretamente como objeto. Mas aqui não falamos do espaço concreto, matemático, geométrico, cujas características físicas permitem a mensuração e quantificação. Adentramos ao espaço vivido, ou seja, uma forma de vivenciar a espacialidade em que transpomos a nós mesmos ao adquirir a habilidade de projetar nossa existência no mundo (Husserl, 1954/2012; Merleau-Ponty, 1945/2006b).

O espaço não é o ambiente (real ou lógico) em que as coisas se dispõem, mas o meio pelo qual a posição das coisas se torna possível. Quer dizer, em lugar de imaginá-lo como uma espécie de éter no qual todas as coisas mergulham, ou de concebê-lo abstratamente com um caráter que lhes seja comum, devemos pensá-lo como a potência universal de suas conexões (Merleau-Ponty, 1945/2006b, p. 328).

O espaço é um dos meios pelo qual nos entrelaçamos ao mundo e a outrem (MerleauPonty, 1945/2006b), pois, mais do que uma localização espacial, ele nos permite ação e movimento e em suas alterações também encontramos uma via possível para alcançar a compreensão das experiências patológicas (Minkowski, 1933/1994; Tatossian, 1979/2006; Messas et al., 2018; Fuchs, 2007a). 
O problema da espacialidade humana, como espaço vivido, compõe um aspecto do esgotamento do devir. Nesses casos, o espaço se revela por meio do prejuízo da proximidade do sujeito como mundo, em seu sentido pré-reflexivo e que sustenta a capacidade humana de se colocar em relação com outrem e com o mundo. Não se trata de um espaço orientado pelos objetos comuns ao ser humano e que o rodeiam, mas de um espaço pático, da ordem do "sentido", e que denotam existência humana em sua mundaneidade. Os distúrbios manifestados no vivido espacial não são compreendidos apenas como sintomas causais, que podem ser explicados, mas como fenômenos em sua essência. As alterações do espaço vivido transbordam em todas as atividades e funções do indivíduo ao compor uma experiência patológica (Tatossian, 1979/2006).

Além da correlação entre o vivido espacial com o vivido temporal, o espaço também se aproxima da esfera corporal, dado este explorado na fenomenológica filosófica de MerleauPonty (1942/2006a; 1945/2006b). Tal aproximação revela que corpo e espaço atingem a unidade dialética $\mathrm{Eu} /$ mundo e não apenas o sujeito isolado, ou seja, é por que temos um corpo que podemos agir e nos movimentar sob o mundo (Souza, Melo, \& Moreira, 2020). Mais do que um objeto situado espacialmente, o corpo habita também o espaço e, com isto, se apossa do mundo (Merleau-Ponty, 1945/2006b).

Resgatar a espacialidade em seu sentido fenomenológico é preponderante para a prática clínica, uma vez que o espaço vivido nos remonta a como o paciente vive no mundo e com os outros em seu sentido pré-reflexivo. Elemento este também experienciado no setting psicoterapêutico, pois, como afirma Fuchs (2007a), a relação psicoterapêutica se configura como uma espécie de extensão do espaço vivido do paciente.

Em uma experiência patológica, o espaço vivido é deformado, inibido e constrito diante o seu horizonte de possibilidades, os quais incluem experiências no âmbito da percepção, ação, imaginação, emoção, e etc. (Souza, Melo, \& Moreira, 2020; Messas et al., 2018; Fuchs, 2007a; Tatossian, 1979/2006). Nesse sentido, a tarefa de uma prática clínica situada numa perspectiva fenomenológica é "explorar e compreender o espaço vivido do paciente a fim de reabrir seu horizonte de possibilidades" (Fuchs, 2007a, p. 437). E o caminho para se realizar tal tarefa é uma ação interativa, dialética, que ocorre no entrelaçamento dos mundos vividos do paciente e do psicoterapeuta (Fuchs, 2007a). 


\section{O Outro ${ }^{1}$}

A última categoria que apresentamos aqui para uma compreensão do vivido patológicos se volta para a intersubjetividade, para a relação com Outrem. Como sinaliza Messas et al. (2018), "estamos sintonizados entre si através de um contato direto e prétemático com o comportamento expressivo dos outros" (p. 02), sendo este um fio condutor significativo de nosso engajamento ambíguo no mundo (Merleau-Ponty, 1945/2006b).

Ao mesmo tempo em que a subjetividade humana constitui o Outro, ela também é constituída por ele como alteridade na intersubjetividade (Tatossian, 1994). Aqui Outrem não é apenas um Eu diferente de mim; um objeto estranho, alheio e separado. Em uma perspectiva eminentemente ambígua, podemos compreender também o "Eu mesmo como o Outro" (Tatossian, 1994, p. 290). Em outras palavras, há uma fronteira borrada que impede tanto uma cisão completa quanto a independência entre Eu/Outro. Trata-se de um equilíbrio dialético que nunca se conquista definitivamente, mas que devemos buscar na medida em que nossa existência é demarcada pela presença e pela invasão do outro que marca nossa radical coexistência (Merleau-Ponty, 1945/2006b). Nas palavras de Tatossian (1994), "não há expectativa de intersubjetividade sem afetar a subjetividade, não mais do que uma folha de papel não tem frente sem verso" (p. 291).

O Outro também significa uma forma de mim mesmo, pois sou Eu que o compreendo como tal. Porém, algo desta apreensão sempre escapa. Ao mesmo tempo, esse movimento revela uma alteridade que em seu sentido contrário mostra em mim mesmo o Outro, que até então era um estrangeiro para mim (Tatossian, 1994).

Outrem me transforma em objeto e me nega, eu transformo outrem em objeto e o nego, diz-se. Na realidade, o olhar de outrem só me transforma em objeto, e meu olhar só o transforma em objeto se nós dois nos retirarmos para o fundo de nossa natureza pensante, se nós dois olhamos de modo inumano, se cada um sente suas ações, não retomadas e compreendidas, mas observadas como as ações de um inseto. É isso que acontece, por exemplo, quando sou olhado por um desconhecido (Merleau-Ponty, 1945/2006b, p. 484).

É nesse distanciamento e nessa recusa de algo em mim, que nasce Outrem para mim (Merleau-Ponty, 1945/2006b). Tal ambiguidade só é possível, como assinala Merleau-Ponty (1945/2006b), devido à percepção, pois só apreendemos Outrem por meio de nossa própria 
compreensão dele e do que o cerca, embutindo aí um conjunto de significações. Se a partir de Merleau-Ponty experienciamos a nossa própria subjetividade como encarnada, a questão na relação com o outro é como esses outros corpos aparecem para nós. A inacessibilidade da experiência do outro é o preço que pagamos para estarmos no mundo com os outros (Overgaard \& Henriksen, 2019).

Apesar de esta discussão incitar certo esforço filosófico, estes elementos são fundantes dos quadros clínicos patológicos, pois neles encontramos uma desproporção da unidade dialética Eu/Outro/Mundo (Tatossian, 1979/2006; 1994). Na experiência de adoecer, é possível observar diferentes formas alteradas de se relacionar com os outros, de percebê-los e, de forma mais ampla, de estabelecer a fronteira entre o eu e o não-eu, como presente na experiência de esquizofrenia (Overgaard \& Henriksen, 2019).

No sentido de uma fenomenologia clínica da ambiguidade, cabe ao clínico uma abordagem terapêutica que lhe permita o acesso aos aspectos já constituídos da experiência singular e subjetiva de seu paciente $(\mathrm{Eu})$ e, simultaneamente, de seus dados originários, préreflexivos e que fundam a gênese constitutiva do mundo vivido (psico)patológico em questão. É um processo também ambíguo, em que paciente e clínico - Eu/Outrem - se entrelaçam num campo de significados.

\section{O Mundo Vivido (psico)Patológico na Depressão Melancólica e na Esquizofrenia}

Tatossian (1979/2006) aponta para as psicoses como a grande questão para a fenomenologia psiquiátrica de sua época, dado o grau de incompreensibilidade psicológica que as cercam. Desde o início desta área, grandes são os esforços de construção de sólidos eixos teóricos para compreender esses modos de funcionamento, sobretudo, quando se trata da depressão melancólica e da esquizofrenia.

Encontramos diversos estudos, desde a fenomenologia psiquiátrica tradicional (Minkowski, 1933/1994; Binswanger, 1960/2005) à fenomenologia clínica contemporânea (Tatossian, 1979/2006; Fuchs, 2010; 2018; Messas et al., 2018; Irarrázaval, 2015; 2018) que apresentam discussões sobre o tempo, o corpo, o espaço e o Outro relacionados a estes quadros (psico)patológicos. Aqui, nosso esforço será o de apresentar simultaneamente as quatros categorias que possibilitam o aparecimento destes modos de adoecer na depressão melancólica e na esquizofrenia, tendo como fio condutor o mundo vivido (Lebenswelt).

Inicialmente, o mundo vivido na depressão melancólica encontra na tristeza um sintoma que a revela como fenômeno. O modo de ser global do depressivo, como aponta 
Tatossian (1979/2006) ilustra uma "experiência de emurchecimento e definhamento do vivido" (p. 113), em que o sofrimento, inexprimível e inesgotável, aparece de forma pervertida e anormal. Trata-se de uma tristeza vital, em que emergem sentimentos de vazio e petrificação (Tatossian, 1979/2006; 1983/2012a).

Diante o caráter vital da tristeza, nos deparamos com a dinâmica da corporeidade na depressão melancólica, uma vez que o sofrimento e a dor são primeiramente percebidos sensorial e, portanto, corporalmente, o que pode ser ilustrado pelas sensações de peso no peito, dor na garganta, aperto, falta de apetite, e etc., que marcam características de inatividade, impotência e pobreza de ações, gestos e etc. (Tatossian, 1979/2006; 1983/2012a).

Esta ressonância corporal ilustra a dinâmica e a globalidade do corpo próprio vivido na união do corpo sujeito e do corpo objeto (Merleau-Ponty, 1945/2006b). Na depressão melancólica, há um prejuízo na constituição desta relação, uma vez que o depressivo perde a habilidade de se colocar no mundo como corpo objeto. Este último é o núcleo vital de nossa afetividade, além de ser a ponte que nos permite agir sobre o mundo. Não podendo experienciar a corporeidade como objeto, o depressivo se vê anestesiado afetivamente e inibido em suas possibilidades de devir (Tatossian, 1979/2006; 1982/2012c).

Há uma identificação quase que exclusiva como corpo sujeito, tornando-se distante e cada vez mais apagado de Outrem e do mundo. Impossibilitado de agir, cada movimento reflete um esforço monumental e o corpo é vivido como peso insuportável, como carga. Enquanto o corpo é pesado, o espaço se esvazia numa relação paradoxal (Tatossian, 1979/2006; 1982/2012c). Cada vez mais preso e incapaz de se projetar no mundo, o depressivo esbarra em uma existência vazia e desprovida de qualquer suporte que o auxilie. Como afirma Tatossian (1983/2012a), “o deprimido perde a proximidade existencial com o mundo, que aparece longínquo, vago, fora de seu alcance” (p. 115), e neste prejuízo encontramos a alteração no vivido espacial que se encontra vazio.

O mundo e as coisas que o compõem estão isolados para o depressivo, fora de seu alcance, pois há uma perda da profundidade espacial em que esta só é acessada pela racionalidade devido a falta de comunicação vital com o mundo e, por consequência, do prejuízo no contato afetivo e sensorial com ele. Esvaziado, o espaço é sentido como levitação e queda (Tatossian, 1979/2006).

Atrelado às dimensões do corpo e do espaço, o tempo é vivido como abertura diante o horizonte de possibilidade que sustenta nossa existência enraizada no mundo (Merleau-Ponty, 1945/2006b). Entretanto, a gênese constitutiva do tempo na depressão melancólica se desvela na paralisação desse fluxo contínuo, uma vez que a ruptura na comunicação com o mundo 
impede a projeção, o lançar-se do sujeito em seu horizonte experiencial (Tatossian, 1979/2006).

A inibição do devir, como assinala Tatossian (1979/2006), é o eixo principal da alteração do vivido temporal na depressão melancólica. Há uma dessincronização da experiência do tempo, e o tempo vivido no depressivo perde a sincronicidade com o tempo do mundo encontrando-se inibido, estagnado e desacelerado. Impossibilitado de se lançar ao futuro, o depressivo prende-se ao passado em um estado de anestesia afetiva distante de qualquer perspectiva futura. Sem qualquer vislumbre do porvir, o depressivo é tentado constantemente a remoer o passado como forma de buscar modificá-lo (Tatossian, 1979/2006; Fuchs, 2010).

A impossibilidade de agir o leva a tentar mudar o que já aconteceu fruto da perda de comunicação com o mundo, a qual reverbera também em uma perda de comunicação com Outrem. Ao perder a confiança no mundo, estrangeiro e ameaçador, o depressivo fecha-se em si mesmo, alienando-se. Vale destacar que esses processos não são conscientes. Não falamos aqui de uma perda de confiança como elemento psicológico, mas num sentido pré-reflexivo (Souza \& Moreira, 2019; Tatossian, 1979/2006; 1982/2012c).

A perda de confiança no mundo ressoa como perda de confiança em si mesmo, confirmada na impossibilidade do depressivo agir e se movimentar. Em depressões mais leves, o paciente tende a se colar em Outrem como forma de substituir sua falta de confiança pessoal ao conquistar a aceitação do Outro. Porém, em casos mais graves de depressão melancólica essa substituição falha é descartada e o depressivo fecha-se completamente em si mesmo e descarta Outrem como possibilidade acessória (Souza \& Moreira, 2019; Tatossian, 1979/2006; 1982/2012c).

Já no mundo vivido esquizofrênico, podemos afirmar que este é o terreno contemporâneo mais fértil da psicopatologia fenomenológica devido à quantidade e à qualidade de estudos e pesquisas que têm sido desenvolvidos nas últimas décadas e também, como mencionado acima, à fecundidade da lente fenomenológica no campo das psicoses. $\mathrm{Na}$ esquizofrenia, também encontramos perturbações em todas as categorias, o que tem sido atribuído à alterações da consciência de si (Irarrazaval, 2018; Englebert, Stanghellini, Valentiny, \& Fuchs, 2018).

Tomando como base a clássica fórmula proposta por Wolfgang Blankenburg que sugere a perda da evidência natural do sujeito esquizofrênico, considera-se esta experiência muito além da dimensão cognitiva ou intelectual. Ela "se ancora em um modo de ser-no- 
mundo mais profundo que atinge problemáticas subjetivas, corporais e intersubjetivas" (Englebert et al., 2018, p. 78).

A problemática esquizofrênica atinge a vida cotidiana e as proporções dialéticas em suas relações, o que institui na lente fenomenológica a dimensão da vulnerabilidade na perturbação da proporção antropológica e o alcance clínico de se buscar restabelecer tais proporções desequilibradas no vivido esquizofrênico (Tatossian, 1984/2012b). É importante ressaltar que esta compreensão fenomenológica se distancia de olhares deficitários da esquizofrenia (Sass, 2017) e caminha para a hipótese de um excesso de funcionamento da consciência que servirá aqui de fundo para expormos as alterações ligadas ao corpo, ao tempo, ao espaço e ao Outro no mundo vivido esquizofrênico.

A psicopatologia fenomenologia contemporânea reconhece a esquizofrenia como um distúrbio paradigmático ligado às alterações da corporeidade e da intersubjetividade (Irarrázavel, 2015; Stanghellini, 2009). A característica essencial da existência esquizofrênica seria a descorporificação ${ }^{2}$, ou seja, um comprometimento fundamental do modo de vivenciar o próprio corpo (Fuchs, 2018). Ao considerarmos a presença do corpo vivido em todos os sentimentos, percepções e ações, no funcionamento esquizofrênico há uma perda deste assentamento corporal. Os indivíduos “não 'habitam' mais seus corpos, justamente no sentido da realização familiar e habitual da vida" (Fuchs, 2018, p. 190). Trata-se de uma "perturbação fundamental da pessoa em sua capacidade de se orientar por sua corporeidade inteiramente com vistas ao mundo comum e participar dele" (Fuchs, 2018, p. 190).

Diante da alienação do próprio corpo, do mundo exterior e mesmo da separação entre eles, não há contato verdadeiro com o Outro. Borra-se os limites entre si mesmo e Outrem (Koch, Kolter, Fuchs, Sattel, \& Kelbel, 2017), perdendo aquilo que é comum e que marca a intersubjetividade. É comum a existência de mal entendidos e confusões acerca de significados nas interações dos pacientes com os outros, como uma perda de sincronia na interação social que impede a coordenação de significados e mesmo dificulta a incorporação da perspectiva dos outros (Irarrázaval, 2015).

Há uma espécie de alienação, em que o mundo factual apresenta regras, um sentido próprio e um funcionamento que o esquizofrênico não consegue acessar livremente. Esta ruptura se desvela por meio da fragmentação do arco intencional do mundo vivido esquizofrênico. Há uma perda na continuidade deste arco, uma vez que ele se dissolve e a cadeia de protensões se perde. Nesse sentido, emergem lacunas temporais, que resultam na falta de significados sobre o que é vivenciado. Cabe, então, ao paciente o exercício contínuo 
de preenchimento de tais lacunas por meio de uma reconstrução racional e hiperreflexiva comum nos estágios iniciais da psicose (Fuchs, 2010).

A quebra na cadeia de protensões do arco intencional esquizofrênico traz o porvir impregnado por absoluto espanto, surpresa, como algo externo e alheio, mesmo que se trate dos próprios pensamentos do indivíduo. Estes são reconhecidos como estrangeiros e, ao invés de dar continuidade ao arco intencional, tornam-se obstáculos (Fuchs, 2007b; 2010). Como assinala (Fuchs, 2007b), "um pensamento que invade o arco intencional fragmentado carece do senso de gerência; não é mais meu. Aparece contra a minha intenção e 'me fala' como se fosse uma força alienígena" (p. 234). É como se, de alguma forma, ele tivesse sido introduzido ali, como vozes que escuto e que vêm de fora. É nesse sentido que a esquizofrenia sempre se desvela como um transtorno da intersubjetividade básica (Fuchs, 2010).

A fragmentação temporal no mundo vivido esquizofrênico se sobrepõe ao espaço que se torna estático. Como afirma Fuchs (2010), "há um enfraquecimento dos aspectos dinâmicos e flexíveis da vida e uma hipertrofia correspondente dos elementos fixos, racionais e geométrico" (p. 17). A descorporificação na esquizofrenia, atrelada à fragmentação do arco intencional da temporalidade, impede o esquizofrênico de habitar o espaço e se movimentar livre e espontaneamente sobre ele.

A habitação é um aspecto central para o espaço vivido (Merleau-Ponty, 1945/2006b; Fuchs, 2007a). Por meio de nossa subjetividade encarnada e que se desvela na duração do horizonte temporal, o espaço se abre diante de nós como fundo sob o qual toda ação e comunicação é possível. Mas, no mundo vivido esquizofrênico, a dinâmica espacial se altera uma vez que o mundo é desconhecido, estrangeiro e pouco familiar. Nesse sentido o espaço é vivido como ameaçador em uma atmosfera de profunda insegurança, em que o esquizofrênico tem dificuldade em se mover ou escapar (Toma \& Fuchs, 2018).

A perda da evidência natural modifica radicalmente a dinâmica do espaço vivido na esquizofrenia devido à falta de sincronia entre o espaço pessoal e imanente a cada sujeito e o espaço social, físico, que demanda interação e comunicação com as pessoas e com o mundo; elementos esses alheios ao esquizofrênico (Toma \& Fuchs, 2018).

\section{Considerações Finais}

A fenomenologia clínica tem como tarefa buscar meios de acesso e compreensão dos mundos vividos (psico)patológicos. Essa é uma tarefa delicada, pois nos leva a tentar alcançar mais do que as alterações das experiências de adoecer por meio do método descritivo. Vamos 
além e caminhamos em direção à gênese constitutiva desses mundos vividos, ou seja, buscamos o seu fundamento constitutivo e constituinte simultaneamente como ponto de ancoragem de nossa existência intersubjetiva no mundo.

Diante de tal empreitada surgem estudos desde a tradição clássica da fenomenologia psiquiátrica até o contexto contemporâneo da fenomenologia clínica sobre as bases que fundam as experiências (psico)patológicas, sendo elas, a saber: o corpo, o tempo, o espaço e o Outro. Elas são as condições que possibilitam o desvelamento dos mundos vividos (psico)patológicos e em suas alterações encontramos o fio condutor necessário para a compreensão dos vários modos de funcionamento das experiências de adoecimento mental, tais como a depressão melancólica e a esquizofrenia. Ou seja, as categorias fenomenológicas trazem um norte para se compreender aquilo que é comum nas experiências de adoecer e que revelam diferentes modos de funcionamento. Consideramos que se trata de uma ferramenta essencial tanto para uma via de compreensão diagnóstica, quanto para a composição de uma prática clínica que possa recorrer aos aportes da psicopatologia fenomenológica.

É importante enfatizarmos que, uma fenomenologia clínica da ambiguidade, não cede à objetivação das experiências de adoecer, pois mantém o compromisso também com a subjetividade. Objetiva-se o campo comum da experiência de adoecer sem abrir mão da singularidade que marca toda experiência. Trata-se de um desafio que perpassa o campo clínico e que torna possível o encontro, ao mesmo tempo, com o outro e também com sua experiência de adoecer.

Por fim, resgatar as categorias fenomenológicas e descrevê-las como parte dos quadros da depressão melancólica e da esquizofrenia representa um esforço conjunto para clarificar o modo de funcionamento destes mundos vividos, uma vez que o vivido (psico)patológico se desvela na intersubjetividade do contato do clínico com o seu paciente. Destaca-se ainda a necessidade do desenvolvimento de pesquisas que aliem a fecundidade teórica da psicopatologia fenomenológica e o contato com a experiência descrita por aqueles que a vivenciam.

\section{Referências}

Binswanger, L. (2005) Mélancolie et manie: Etudes phénoménologiques. Paris: Presses Universitaires de France. (Obra original publicada em 1960)

Bloc, L., Moreira, V., Wolf-Fédida, M., \& Chamond, J. (2017). Lá relation d'implication (et non d'application) entre lés phénoménologies philosophiques et cliniques: Lê point de 
Camila Pereira de Souza, Lucas Guimarães Bloc, Virginia Moreira

vue d'Arthur Tatossian. Bulletin de psychologie, 70(4), 301-309. doi:10.3917/bupsy.550.0301

Englebert, J., Stanghellini, G., Valentiny, C., Follet, V., Fuchs, T., \& Sass, L. (2018). Hyper reflexivity and the first-person perspective: A decisive contribution of contemporary phenomenological psychopathology to the understanding of schizophrenia. L'Évolution Psychiatrique, 83(1), 77-85. doi:10.1016/j.evopsy.2017.07.004

Fuchs, T. (2007a). Psychotherapy of the lived space: A phenomenological and ecological concept. American Journal of Psychotherapy, 61(4), 422-439. doi:10.1176/appi.psychotherapy.2007.61.4.423

Fuchs, T. (2007b). The temporal structure of intentionality and its disturbances in schizophrenia. Karger, 40(4), 229-235. doi:10.1159/000101365

Fuchs, T. (2010). Temporality and Psychopathology. Phenomenology and the Cognitive Sciences, 12, 75-104. doi:10.1007/s11097-010-9189-4

Fuchs, T. (2018). Si mesmo e esquizofrenia. In T. Fuchs, Para uma psiquiatria fenomenológica: Ensaios e conferências sobre as bases antropológicas da doença psíquica, memória corporal e si mesmo ecológico (pp. 183-206). Rio de Janeiro: Via Verita.

Heidegger, M. (2015). Ser e Tempo. Rio de Janeiro: Vozes. (Obra original publicada em 1927)

Husserl, E. (1994). Lições para uma fenomenologia da consciência interna do tempo. Lisboa: Casa da Moeda. (Obra original publicada em 1928)

Husserl, E. (2012). A crise das ciências européias e a fenomenologia transcendental. Rio de Janeiro: Forense Universitária. (Obra original publicada em 1954)

Irarrázavel, (2015). Lived body in schizophrenia. Transition from basic self-disorders to fullblown psychosis. Frontiers in Psychiatry, 6(9), 1-8. doi:10.3389/fpsyt.2015.00009

Irarrázavel, (2018). Vulnerability in schizophrenia: A phenomenological anthropological approach. InterCultural Philosophy, (1), 157-167. doi:10.11588/icp.2018.1.48070

Koch, S., Kolter, A., Fuchs, T., Sattel, H., \& Kelbel, J. (2017). (Dis-)Embodiment in Schizophrenia: Effects of Mirroring on Self-Experience, Empathy, and Wellbeing. In V. Karkou, S. Oliver, \& S. Lycouris (Eds.), The Oxford Handbook of Dance and Wellbeing (pp. 863-882). Oxford: Oxford University Press.

Melo, A. K., Araújo, V. V., Bloc, L., \& Moreira, V. (2016). A Experiência do Tempo em Merleau-Ponty: Contribuições para a Fenomenologia Clínica, Interação em Psicologia, 20(1), 10-19. doi:10.5380/psi.v20i1.32798 
Merleau-Ponty, M. (2006a). A estrutura do comportamento. São Paulo: Martins Fontes. (Obra original publicada em 1942)

Merleau-Ponty, M. (2006b). Fenomenologia da Percepção. São Paulo: Martins Fontes. (Obra original publicada em 1945)

Messas, G., Tamelini, M., Mancini, M., \& Stanghellini, G. (2018). New perspectives in phenomenological psychopathology: Its use in psychiatric treatment. Front. Psychiatric, 9(466), 01-05. doi:10.3389/fpsyt.2018.00466

Minkowski, E. (1994). Le temps vécu. Paris: Presses Universitaires de France. (Obra original publicada em 1933)

Overgaard, S., \& Henriksen, M. G. (2019). Alterity. In G. Stanghellini, M. Broome, A. Raballo, A. Vincent Fernandez, P. Fusar-Poli, \& R. Rosfort (Eds.), The Oxford Handbook of Phenomenological Psychopathology (pp. 381-389). Oxford: Oxford University Press.

Sass, L. (2017). Madness and modernism: Insanity in the light of modern art, literature. Oxford: Oxford University Press.

Souza, C., \& Moreira, V. (2019). Tristeza, depressão e suicídio melancólico: A relação com o Outro. Arquivos Brasileiros de Psicologia, 70(2), 173-185. Recuperado de http://pepsic.bvsalud.org/scielo.php?script=sci_arttext\&pid=S1809$52672018000200013 \& \operatorname{lng}=\mathrm{pt} \& \operatorname{lng}=\mathrm{pt}$

Souza, C., Melo, A. K., \& Moreira, V. (2020). The lived space of Ana: A clinical case study from the perspective of phenomenological psychopathologie. Trends in Psychology, 28, 16-30. doi:10.9788/s43076-019-00010-5

Stanghellini, G. (2009). Embodiment and schizophrenia. World Psychiatry, 8, 56-59. doi:10.1002/j.2051-5545.2009.tb00212.x

Tatossian, A. (1994). La subjectivité. In D. Widlöcher (Dir.), Traité de psychopathologie (pp. 253-318). Paris: Presses Universitaires.

Tatossian, A. (2006). A fenomenologia das psicoses. São Paulo: Escuta. (Obra original publicada em 1979)

Tatossian, A. (2012a). Depressão, vivido depressivo e orientação terapêutica. In. A. Tatossian \& V. Moreira, Clínica do Lebenswelt: Psicoterapia e psicopatologia fenomenológica (pp. 109-128). São Paulo: Escuta. (Obra original publicada em 1983)

Tatossian, A. (2012b). Fenomenologia da esquizofrenia. In. A. Tatossian \& V. Moreira, Clínica do Lebenswelt: Psicoterapia e psicopatologia fenomenológica (pp. 131-18). São Paulo: Escuta. (Obra original publicada em 1984) 
Tatossian, A. (2012c). Fenomenologia do corpo. In. A. Tatossian \& V. Moreira, Clínica do Lebenswelt: Psicoterapia e psicopatologia fenomenológica (pp. 101-107). São Paulo: Escuta. (Obra original publicada em 1982)

Toma, S., \& Fuchs, T. (2018). Inhabiting the Shared World: Phenomenological considerations on sensus communis, social space and schizophrenia. In I. Hipólito, J. Gonçalves, \& J. G. Pereira (Eds.), Schizophrenia and Common Sense: explaining the relation between madness and social values (pp. 19-38). Lisboa: Springer.

Zahavi, D. (2015). A Fenomenologia de Husserl. Rio de Janeiro: Via Verita.

\section{Endereço para correspondência}

\section{Camila Pereira de Souza}

Av. Washington Soares, 1321, Edson Queiroz, Fortaleza - CE, Brasil. CEP 60811-905

Endereço eletrônico: camila_psouza@ hotmail.com

\section{Lucas Guimarães Bloc}

Av. Washington Soares, 1321, Edson Queiroz, Fortaleza - CE, Brasil. CEP 60811-905

Endereço eletrônico: bloclucas@gmail.com

\section{Virginia Moreira}

Av. Washington Soares, 1321, Edson Queiroz, Fortaleza - CE, Brasil. CEP 60811-905

Endereço eletrônico: virginiamoreira@unifor.br

Recebido em: 02/07/2020

Aceito em: 11/09/2020

\footnotetext{
Notas

* Psicóloga, graduada pela Universidade de Fortaleza, Mestre e Doutoranda pela Universidade de Fortaleza, professora do Centro Universitário Farias Brito.

** Graduado e mestre em Psicologia pela Universidade de Fortaleza (UNIFOR). Doutor em Psicopatologia pela Université Paris VII. Professor do curso de Psicologia da UNIFOR.

*** Doutora em Psicologia Clínica pela Pontíficia Universidade Católica de São Paulo (PUC-SP). Pós-Doutora em Antropologia Médica pela Harvard Medical School. Professora Titular do Programa de Pós-Graduação em Psicologia da Universidade de Fortaleza (UNIFOR).

${ }^{1}$ O termo Outro é utilizado por Arthur Tatossian em maiúsculo como alusão à relação intersubjetiva sujeito/mundo. Neste artigo, optamos por manter a grafia original como foi utilizada por Tatossian.

2 Diante das diferentes possibilidades e da dificuldade de tradução, optamos por traduzir a palavra desimbodiment por descorporificação.
} 
Financiamento: A pesquisa relatada no manuscrito foi financiada pela bolsa de doutorado da primeira autora (CAPES) e pela bolsa de produtividade em pesquisa da terceira autora $(\mathrm{CNPq}-\mathrm{PQ}-1)$.

Este artigo de revista Estudos e Pesquisas em Psicologia é licenciado sob uma Licença Creative Commons Atribuição-Não Comercial 3.0 Não Adaptada. 